\title{
Indicadores de sustentabilidade para a gestão municipal de resíduos sólidos urbanos: um estudo para São Carlos (SP)
}

\author{
Indicators of sustainability for municipal solid waste management: case study \\ of the city of São Carlos (SP)
}

\begin{abstract}
Carla Natacha Marcolino Polaz
Bióloga. Especialista em Gerenciamento Ambiental pela Universidade de São Paulo (USP). Mestre em Engenharia Urbana pela Universidade Federal de São Carlos (UFSCar). Analista Ambiental do Instituto Chico Mendes de Conservação da Biodiversidade
\end{abstract}

\section{Bernardo Arantes do Nascimento Teixeira}

Engenheiro civil. Professor Doutor do Programa de Pós-Graduação em Engenharia Urbana da UFSCar

\begin{abstract}
Resumo
Uma forma de operacionalizar o conceito de sustentabilidade é por meio da utilização de indicadores, um instrumento que pode auxiliar os gestores públicos no processo decisório. Este trabalho teve como objetivo a proposição de indicadores de sustentabilidade para a gestão de Resíduos Sólidos Urbanos (RSU) em São Carlos (SP), sob a perspectiva de cinco dimensões: ambiental, econômica, social, política e cultural. A estratégia adotada para a elaboração dos indicadores foi a identificação dos problemas prioritários para a gestão de RSU por meio de consultas aos gestores municipais. Isto resultou em um conjunto de 15 indicadores, cujos valores expressam sua tendência favorável, desfavorável ou muito desfavorável à sustentabilidade. Esta experiência mostrou que a implementação de um sistema de indicadores deve envolver a participação de diferentes agentes sociais, a fim de legitimar o uso efetivo desta importante ferramenta.
\end{abstract}

Palavras-chave: indicadores de sustentabilidade; resíduos sólidos urbanos; políticas públicas; gestão ambiental.

\section{Abstract}

One way to operationalize the concept of sustainability is through the use of indicators, an important tool to guide the public managers in the process of making decisions. The objective of this paper was the proposition of sustainability indicators for public management of Municipal Solid Waste (MSW) in São Carlos (SP), from the perspective of five dimensions: environmental, economic, social, political and cultural. The strategy adopted for the indicators development was the identification of priority problems for the MSW management, by interviewing the municipal managers. The results include a set of 15 sustainability indicators, as their values express three trends: favorable, unfavorable or very unfavorable to sustainability. This research showed that the development of a local indicator system should involve different actors in order to legitimize the effective use of this useful management tool.

Keywords: sustainability indicators; municipal solid waste; public policy; environmental management.

\section{Introdução}

As altas taxas de consumo e a crescente produção de resíduos estão entre os maiores problemas ambientais enfrentados pela humanidade. É óbvio que o problema se agrava com a expansão e o adensamento dos aglomerados urbanos, já que a infraestrutura sanitária da maioria das cidades brasileiras não acompanha o ritmo acelerado desse crescimento.

Estatísticas divulgadas pelo Instituto Brasileiro de Geografia e Estatística (IBGE, 2002), oriundas da Pesquisa Nacional de
Saneamento Básico, revelam que, no Brasil, os sistemas de limpeza urbana coletam em torno de 150 mil toneladas de resíduos sólidos urbanos (RSU) por dia. Do total de municípios, 63,6\% despejam seus resíduos em lixões, 18,4\% em aterros controlados e apenas 13,8\% utilizam aterros sanitários (IBGE, 2002). Agravando este quadro, o setor sofre com a falta de diretrizes por parte do governo federal, uma vez que a Política Nacional de Resíduos Sólidos ainda aguarda votação no congresso.

Um dos desafios da construção do desenvolvimento sustentável é criar instrumentos de mensuração capazes de prover informações 
que facilitem a avaliação do grau de sustentabilidade das sociedades, monitorem as tendências de seu desenvolvimento e auxiliem na definição de metas de melhoria. Os indicadores de sustentabilidade têm sido utilizados também como forma de melhorar a base de informações sobre o meio ambiente, auxiliar a elaboração de políticas públicas, simplificar estudos e relatórios e assegurar a comparabilidade entre diferentes regiões (IBGE, 2008; MILANEZ; TEIXEIRA, 2003). O trabalho com os indicadores de sustentabilidade pode ajudar a enxergar as ligações entre os diferentes aspectos do desenvolvimento dentro dos vários níveis em que eles coexistem e apreciar a complexa interação entre as suas diversas dimensões (OECD, 2006)

Como qualquer outra ferramenta de gestão, os indicadores possuem uma série de limitações técnicas. A maioria dos indicadores relacionados à sustentabilidade não possui um sistema conceitual único; medem a aproximação da realidade, e não a realidade precisamente (VAN BELLEN, 2005). Além disso, a seleção inadequada de indicadores conduz a um sistema deficiente, muitas vezes ambíguo e, portanto, passível de manipulação política ou de interpretações 'produzidas' ou 'instituídas' da realidade. Logo, antes de utilizá-los, recomenda-se apontar para o aspecto complementar dos indicadores: sua leitura e interpretação devem ser acompanhadas de uma análise minuciosa do fenômeno em questão (KAYANO; CALDAS, 2002).

Dentre os indicadores relacionados aos RSU, o mais utilizado no Brasil e no mundo é aquele que mede a quantidade gerada de resíduos/habitante/tempo. Outro indicador largamente medido se refere à recuperação de resíduos municipais, percebido como o conjunto de operações (reciclagem, reutilização e/ou compostagem) que permite o aproveitamento total ou parcial dos resíduos. Seu cálculo percentual é feito a partir da razão entre o total anual de resíduos municipais recuperados e o total anual de resíduos municipais gerados (XARXA, 2000).

No setor de saneamento ambiental, especialmente para os municípios de pequeno e médio porte, é premente a necessidade de intensificar a participação do Poder Público, em diferentes esferas, quanto à implementação de programas com vistas a aperfeiçoar as condições e as ferramentas de gestão dos seus resíduos sólidos. Em termos de políticas públicas, uma das grandes limitações é que os programas de governo são concebidos para um horizonte de curto prazo, quando deveriam ser planejados na escala de tempo da sustentabilidade, ou seja, pensados para várias gerações. Ao mesmo tempo, não é simples instrumentalizar um conceito que, à primeira vista, parece demasiadamente "impreciso" (POLAZ; TEIXEIRA, 2007).

Dada a fragilidade institucional em que se encontra a grande parte das prefeituras brasileiras, e tendo o município de São Carlos (SP) como objeto de estudo, o objetivo geral deste trabalho foi propor um conjunto de indicadores de sustentabilidade para a gestão municipal de RSU a partir do levantamento de problemas e da identificação de prioridades por meio de consulta aos gestores municipais.

\section{Metodologia}

A metodologia adotada para o desenvolvimento deste trabalho foi dividida em três etapas:

1. levantamento dos principais problemas relacionados à gestão pública de RSU no Brasil;

2. entrevistas com os gestores municipais envolvidos na gestão de RSU em São Carlos (SP) para identificação de prioridades locais;

3. proposição de um conjunto de indicadores de sustentabilidade para monitorar a gestão de RSU em São Carlos.

Para subsidiar a consulta aos gestores municipais, foi elaborada uma lista sistematizada de problemas relacionados à gestão de RSU. Para tanto, foram consultados diversos documentos de origem institucional, como guias de saneamento, relatórios e inventários de resíduos, processos jurídicos e Agendas 21 locais, além de publicações científicas. Em seguida, os problemas foram agrupados em categorias de acordo com cinco dimensões da sustentabilidade: 1) dimensão ambiental/ecológica; 2) dimensão econômica; 3) dimensão social; 4) dimensão política/institucional; e 5) dimensão cultural.

A gestão municipal de RSU em São Carlos é compartilhada por duas secretarias distintas: Secretaria Municipal de Obras e Serviços Públicos (SMOSP) e Secretaria Municipal de Desenvolvimento Sustentável, Ciência e Tecnologia (SMDSCT). A primeira é responsável pela limpeza urbana, coleta, transporte e disposição final dos resíduos domiciliares; cabe à segunda assessorar o programa municipal de coleta seletiva e desenvolver campanhas de educação e sensibilização ambiental junto à população (PREFEITURA MUNICIPAL DE SÃO CARLOS, 2007).

Quatro gestores municipais, de ambas as secretarias, foram entrevistados individualmente. No momento, todos ocupavam cargos de gerência dentro da estrutura hierárquica da prefeitura, constituindose em chefes de departamento ou chefes de divisão (nível hierárquico mais baixo em relação ao primeiro). Porém, estas mesmas pessoas eram também executoras de muitas das atividades relacionadas à gestão municipal de RSU.

Antes do início da entrevista propriamente dita, os gestores foram esclarecidos e contextualizados acerca dos objetivos da pesquisa. Procurou-se também nivelá-los quanto à temática da sustentabilidade e sua terminologia. A lista de problemas foi então apresentada aos gestores. Foi solicitado a cada um deles, a partir de sua percepção de gestor, que apontasse, dentre os problemas categorizados, aqueles que podiam ser considerados 'problemas para São Carlos'. Havia a possibilidade de inserção de novos problemas não contemplados pela listagem original.

Os problemas duplamente apontados, isto é, priorizados pelos gestores de ambas as secretarias consultadas, foram considerados problemas com prioridade 1 , ao passo que aqueles apontados por apenas uma das secretarias foram denominados problemas de prioridade 
2. Os demais, não apontados pelos gestores, apesar de terem sido descartados para efeito deste trabalho, foram registrados como problemas de prioridade 3. Uma vez que o desenvolvimento de indicadores é um processo dinâmico e flexível, os problemas considerados prioridade, quando equacionados hoje, deixam de ser. Em contrapartida, problemas secundários para a gestão vigente, se alterada a conjuntura atual, podem se tornar prioridade.

A partir desta priorização dos problemas associados à gestão de RSU em São Carlos, procedeu-se à etapa de seleção e proposição do conjunto local de indicadores de sustentabilidade. Em 2002, Milanez elaborou um modelo de indicadores específicos para RSU, também embasado na temática da sustentabilidade. Este modelo, composto por 12 indicadores, atribui três parâmetros de tendência para avaliar a sustentabilidade expressa por cada indicador: (MD) tendência muito desfavorável, (D) tendência desfavorável e (F) tendência favorável (MILANEZ, 2002)

Posto que o modelo proposto por Milanez se alinha aos princípios de sustentabilidade preconizados neste trabalho, os seguintes critérios foram utilizados para o processo de seleção dos indicadores para São Carlos: quando os indicadores do modelo de Milanez atendiam ao problema apontado pelos gestores, deu-se preferência ao seu uso; nos casos contrários, optou-se pelos indicadores que se relacionavam ao problema, porém, eram provenientes da literatura levantada na base conceitual. Se nenhum dos critérios satisfizesse o atendimento do problema, fazia-se o exercício de formular novos indicadores.

Concentrou-se forte esforço na tentativa de garantir que os indicadores de sustentabilidade propostos, uma vez aplicados, pudessem refletir da maneira mais fiel possível as lacunas e desafios da gestão municipal de RSU em São Carlos. Com a finalidade de auxiliar os gestores públicos no processo de tomada de decisão, a partir destes indicadores, propõe-se a possibilidade do estabelecimento de metas que caminhem para uma gestão de RSU mais favorável à sustentabilidade.

\section{Resultados e discussão}

\section{Identificação de prioridades para gestão municipal de RSU}

Fruto do processo de consulta aos gestores municipais que atuam na gestão de RSU em São Carlos, a Tabela 1 apresenta os problemas selecionados por todos os entrevistados. Tais problemas foram identificados como prioritários para a gestão local, uma vez que refletem os desafios enfrentados pelos gestores rotineiramente.

Os problemas, sistematizados a partir das cinco dimensões da sustentabilidade, foram agrupados em diferentes categorias, mostradas à esquerda da Tabela 1. Algumas categorias não tiveram problemas destacados pelos gestores. A delimitação e nomenclatura destas

Tabela 1 - Problemas selecionados pelos gestores públicos como 'prioridade 1' para a gestão de RSU em São Carlos (SP), organizados a partir de cinco dimensões da sustentabilidade

\section{Dimensão ambiental/ecológica}

1. Impactos ambientais associados aos RSU

2. Licenciamento ambiental

3. Economia de recursos naturais renováveis e não renováveis

1.1.a. Presença de RSU nas vias e terrenos públicos/privados 1.1.b. Existência de passivo ambiental (antigos lixões)

1.2.a. Morosidade do processo de aprovação, licenciamento e construção de aterros sanitários

1.3.a. Insuficiência* dos processos de recuperação de resíduos (reaproveitamento, reciclagem e/ou compostagem)

\section{Dimensão econômica}

1. Recursos financeiros e eficiência da gestão de RSU

2.1.a. Ausência de fontes específicas de recursos para a gestão de RSU (autofinanciamento)

2. Geração de trabalho e renda

Não houve problemas selecionados como prioridade nesta categoria

\section{Dimensão social}

1. Universalização dos serviços de RSU

2. Condições do trabalho nas atividades associadas aos RSU

3. Valorização social das atividades relacionadas aos RSU

\section{Não houve problemas selecionados} como prioridade nesta categoria Não houve problemas selecionados como prioridade nesta categoria

3.3.a. Insuficiência de políticas públicas específicas para catadores de resíduos recicláveis

3.3.b. Cadeia produtiva informal ignorada pelo poder público

3.3.c. Dificuldades de acesso a benefícios sociais de natureza pública (como educação, saúde)

\section{Dimensão política/institucional}

1. Institucionalização da gestão de RSU

4.1.a. Ausência de organograma e de plano de carreira para o setor de RSU 4.1.b. Recursos humanos/pessoal inadequado/insatisfatório (quantidade, capacitação, estruturação) 4.1.c. Falta de fiscalização ambiental e aplicação da legislação pertinente

2. Execução da gestão de 4.2.a. Sistema operando de modo deficiRSU

tário e/ou inadequado

4.2.b. Capacidade instalada de operação super/subestimada

4.2.c. Insuficiência de infraestrutura e equipamentos (caminhões compactadores, tratores, balanças, esteiras etc.) 4.2.d. Obsolescência ou falta de manutenção/renovação de estruturas e equipamentos

3. Participação da sociedade na gestão de RSU

Não houve problemas selecionados como prioridade nesta categoria

\section{Geração de RSU}

\section{Dimensão cultural}

\section{1.a. Insuficiência de programas educa-} tivos continuados voltados à questão da minimização da geração e do gerenciamento adequado dos RSU

2. Valores e atitudes da sociedade em relação aos RSU 5.2.a. Insuficiência de atividades de multiplicação de boas práticas em relação aos RSU

* termo "insuficiência" pode significar tanto falta/inexistência quanto inconformidade, inadequabilidade ou deficiência.

categorias seguiram os princípios de sustentabilidade, gerais e específicos ao recorte dos RSU, que evidenciam as dimensões propostas.

$\mathrm{Na}$ dimensão ambiental/ecológica, por exemplo, os princípios ponderados foram: o uso adequado dos recursos naturais (conservação 
e ciclagem); a avaliação de impactos ambientais; a prevenção e compensação por danos ambientais, a precaução (agir com precaução diante da incerteza) e o direito elementar de todos a um ambiente adequado à saúde e ao bem-estar, resultando em três categorias.

Já na dimensão econômica foram considerados os princípios da geração de trabalho e renda, a eficiência econômica da gestão de RSU, a internalização dos custos/benefícios pelos geradores e o princípio do usuário/poluidor-pagador, ou seja, quem usa ou polui assume as consequências. Esses princípios originaram duas categorias, de denominação similar.

Os princípios contemplados na dimensão social foram: a equidade e a universalização (atendimento das necessidades básicas de todos), a cooperação e a participação social, a garantia de condições adequadas de trabalho e a gestão solidária, traduzida como a incorporação digna dos catadores de materiais recicláveis no sistema de RSU. Partindo dessas premissas, os problemas foram organizados em três categorias. A primeira se refere à necessidade de disponibilização dos serviços de RSU a toda a população; a segunda enfoca as condições em que se dá este tipo de trabalho e a terceira faz referência à valorização social de tais atividades.

Caracterizam a dimensão política/institucional princípios como a democratização da informação, a participação e o controle social, assim como a integração das demais dimensões da sustentabilidade. Três categorias foram criadas, duas enfocando os aspectos gerenciais e técnicos da gestão de RSU e uma abordando a questão da participação social neste processo. Esta dimensão foi a única a ter

Tabela 2 - Indicadores de sustentabilidade para a gestão de RSU em São Carlos na dimensão ambiental/ecológica

Indicadores
Dimensão ambiental/ecológica

(1) Quantidade de ocorrências (MD) Mais de X ocorrências/ano a

de lançamentos de RSU em cada 1.000 hab

locais inadequados

(D) Entre X e Y ocorrências/ano a

cada 1.000 hab

(F) Menos de Y ocorrências/ano a

cada 1.000 hab

(2) Grau de recuperação dos passivos ambientais

(MD) As áreas degradadas não foram mapeadas ou não houve recuperação das áreas identificadas (D) As áreas degradadas foram mapeadas, porém não devidamente recuperadas

(F) Todas as áreas degradadas foram devidamente recuperadas

(3) Grau de implementação das medidas previstas no licenciamento das atividades relacionadas aos RSU

(4) Grau de recuperação dos

RSU que estão sob respons-

abilidade do Poder Público

(MD) Inexistência de licenciamento ambiental

(D) Licenciamento ambiental real-

izado, porém, as medidas não foram

plenamente implementadas

(F) Licenciamento ambiental real-

izado e medidas implementadas

integralmente

(MD) Recuperação inexistente ou

muito baixa dos RSU

(D) Recuperação baixa dos RSU

(F) Recuperação alta dos RSU

(MD) Muito desfavorável; (D) Desfavorável; (F) Favoráve problemas adicionados pelos gestores entrevistados durante o processo de consulta.

Inicialmente, visando a contemplar os aspectos mais operacionais da gestão de RSU, havia sido prevista uma sexta dimensão denominada dimensão operacional. Entretanto, ponderou-se que estas questões estão, na realidade, vinculadas à dimensão política/institucional. Por esse motivo, foram propostas duas categorias distintas: a primeira para tratar da institucionalização da gestão e a segunda para tratar da sua execução.

Em virtude dos propósitos enunciados para justificar a implementação de sistemas de indicadores de sustentabilidade por parte do Poder Público, espera-se que os problemas pontuados nesta dimensão direcionem as primeiras ações das administrações municipais no sentido de migrarem para uma gestão 'mais sustentável' de RSU.

Dos princípios que se relacionam à dimensão cultural, destacamse a contextualização e valorização local e a solidariedade entre gerações. Apesar de sua notória relevância, poucos autores consideram a problemática da gestão de RSU como mais um problema de natureza cultural.

Os problemas identificados pelos gestores como prioritários para a gestão municipal de RSU serviram de diretriz para a proposição do conjunto local de indicadores, do qual trata o próximo item.

\section{Proposição de indicadores locais de sustentabilidade para a gestão de RSU em São Carlos}

Da mesma forma que a categorização dos problemas, os indicadores locais para a gestão de RSU foram igualmente organizados, respeitando-se as dimensões da sustentabilidade aqui adotadas. Considerando os problemas identificados pelos gestores, quatro indicadores foram propostos para avaliar a dimensão ambiental/ecológica da gestão municipal de RSU em São Carlos (Tabela 2).

Destes, o primeiro indicador foi adaptado da literatura e os demais modificados a partir do conjunto de Milanez. Em relação ao indicador (1), os dados sobre ocorrências de lançamentos inadequados podem ser obtidos quantificando-se as reclamações motivadas por este tipo de postura, eventuais denúncias, notificações provenientes de ações de fiscalização, diagnósticos diversos, entre outros.

Para a avaliação da tendência à sustentabilidade, uma vez que este indicador é expresso pelo número de ocorrências/tempo/habitante, torna-se necessário, antes de sua aplicação, definir os valores de X e Y. Acima de X ocorrências, o indicador aponta uma situação muito desfavorável; abaixo de Y, situação favorável. O intervalo entre esses valores caracteriza a situação desfavorável à sustentabilidade.

O indicador (2) mede o grau de recuperação dos passivos ambientais pelo Poder Público. Em se tratando da gestão de RSU, em geral, os antigos lixões são responsáveis pela principal forma de passivo ambiental. A avaliação da tendência expressa por esse indicador 
foi baseada em parâmetros qualitativos. Desfrutará de uma condição favorável à sustentabilidade apenas o município que recuperar a totalidade das áreas degradadas pela gestão de RSU. Os casos contrários serão avaliados como desfavoráveis ou muito desfavoráveis.

Outra maneira menos qualitativa e mais quantitativa de avaliação tendencial deste indicador é o estabelecimento de intervalos de valores para os parâmetros (F), (D) e (MD). Por exemplo: pode-se considerar que a tendência favorável à sustentabilidade seja obtida quando houver mais de 90\% de recuperação do passivo; tendência desfavorável se a recuperação das áreas degradadas estiver entre 50 e $90 \%$ e, finalmente, muito desfavorável se a porcentagem de recuperação se situar abaixo de 50\%.

A implementação das medidas previstas no licenciamento das atividades relacionadas aos RSU, do qual trata o indicador (3), refere-se tanto às medidas mitigadoras quanto às medidas compensatórias vislumbradas no processo de licenciamento ambiental. A condição favorável à sustentabilidade ocorre quando o licenciamento ambiental é devidamente realizado e as medidas, implementadas integralmente. Caso as medidas não tenham sido plenamente implementadas, o indicador tende à condição desfavorável. Muito desfavorável ainda são os casos em que o licenciamento ambiental sequer foi realizado.

Especial atenção foi dedicada ao tema abordado pelo indicador (4), ou seja, o grau de recuperação dos RSU. A recuperação pode ser entendida como qualquer sistema ou processo (compostagem, reutilização, reciclagem etc) que retarde o envio do resíduo a uma destinação final qualquer (XARXA, 2000). Como este indicador foi projetado para monitorar exclusivamente os RSU sob responsabilidade do Poder Público, ficam excluídas as situações nas quais a responsabilidade pelo gerenciamento de determinado tipo de resíduo recaia legalmente sobre o seu próprio gerador, como é o caso dos resíduos industriais.

Altas taxas de recuperação de RSU caracterizam a condição mais favorável à sustentabilidade, enquanto a inexistência de qualquer recuperação ou existência em índices muito baixos condicionam a situação mais desfavorável. A critério dos usuários do sistema de indicadores, abre-se a possibilidade de valoração prévia dos adjetivos 'alto', 'baixo' ou 'muito baixo', a fim de tornar o estabelecimento de metas um fenômeno visível numericamente.

Embasando-se nos princípios afeitos à sustentabilidade, uma boa gestão de RSU obrigatoriamente precisa recuperar altas taxas de RSU. Nesse sentido, Grimberg (2005) sintetiza a problemática dos resíduos em pelo menos três grandes desafios: (1) a produção excessiva de resíduos (na contraface do consumo igualmente descontrolado); (2) altos gastos públicos com sistemas convencionais de gerenciamento de resíduos; e (3) ausência de políticas públicas que avancem na direção da recuperação plena dos resíduos, mediante o reaproveitamento e a reciclagem, promovendo condições dignas de trabalho para os catadores.

Um único indicador foi selecionado para representar a dimensão econômica da sustentabilidade na gestão de RSU em São Carlos, uma vez que apenas um problema foi destacado pelos gestores de ambas as secretarias consultadas (Tabela 3). Ao mesmo tempo, entendeu-se que o conteúdo deste indicador satisfaz, por ora, as necessidades do município neste recorte.

Este indicador, proveniente do modelo de Milanez, mede o grau de autofinanciamento da gestão pública de RSU, aferido pela razão anual, em porcentagem, entre os custos autofinanciados dessa gestão e os custos públicos totais. O autofinanciamento compreende as fontes regulares de recursos, como as tarifas de lixo, quando existentes, bem como as fontes eventuais, como recursos garantidos por meio de convênios, projetos ou ainda editais de concorrência pública em âmbito nacional, que financiam serviços específicos da gestão de RSU.

Gozará da condição mais favorável à sustentabilidade o município cujos custos da gestão de RSU forem completamente financiados por fonte específica ou sistema de cobrança dos resíduos, devidamente geridos. A inexistência dessas características, por outro lado, determina a condição mais desfavorável; situações intermediárias, como autofinanciamentos parciais e não cobertura dos custos totais, caracterizam a condição desfavorável à sustentabilidade. Como ocorre em casos anteriores, a critério dos usuários, é possível, ainda, definir faixas de valores para a avaliação tendencial do indicador.

Dois indicadores foram propostos para monitorar a dimensão social da sustentabilidade na gestão de RSU em São Carlos: o primeiro refere-se à universalização dos serviços de RSU e o segundo trata da valorização social deste tipo de atividade (Tabela 4).

Ambos são oriundos do modelo de Milanez, porém, o indicador (6) sofreu modificações mais substanciais. Em seu modelo, para o princípio da universalização dos serviços de RSU, Milanez descreveu o indicador como o percentual da população atendida pela coleta misturada (domiciliar) de resíduos.

Para atender de forma satisfatória às premissas da sustentabilidade, defende-se que o Poder Público deva disponibilizar não apenas os serviços convencionais de RSU, mas serviços diferenciados de coleta, como a coleta de orgânicos para a compostagem e a própria coleta seletiva de recicláveis secos. Ao se garantir a separação prévia dos resíduos, de acordo com a sua tipologia e na sua fonte geradora,

Tabela 3 - Indicadores de sustentabilidade para a gestão de RSU em São Carlos na dimensão econômica

\begin{tabular}{ll}
\hline \multicolumn{1}{|c}{ Indicadores } & Tendência à sustentabilidade* \\
& Dimensão econômica \\
\hline (5) Grau de autofinanciamento da & (MD) Inexistência de fonte especí- \\
gestão pública de RSU & fica ou sistema de cobrança para \\
& financiamento da gestão de RSU \\
& (D) Existência de fonte específica \\
& ou sistema de cobrança para \\
& financiamento da gestão de RSU, \\
& mas não cobre todos os custos \\
& (F) Os custos da gestão de RSU \\
são completamente financiados & por fonte específica ou sistema de \\
cobrança dos resíduos
\end{tabular}

(MD) Muito desfavorável; (D) Desfavorável; (F) Favorável 
Tabela 4 - Indicadores de sustentabilidade para a gestão de RSU em São Carlos na dimensão social

\begin{tabular}{ll}
\hline \multicolumn{1}{c}{ Indicadores } & \multicolumn{1}{c}{ Tendência à sustentabilidade* } \\
\hline $\begin{array}{ll}\text { (6) Grau de disponibilização } \\
\text { dos serviços públicos de RSU à }\end{array}$ & $\begin{array}{l}\text { (MD) Baixa disponibilização dos } \\
\text { população }\end{array}$ \\
& $\begin{array}{l}\text { serviços públicos de RSU } \\
\text { (D) Média disponibilização dos } \\
\text { serviços públicos de RSU } \\
\text { (F) Disponibilização plena dos }\end{array}$ \\
& serviços públicos de RSU \\
(7) Grau de abrangência de & (MD) Inexistência de políticas \\
políticas públicas de apoio ou & públicas efetivas de apoio às pes- \\
orientação às pessoas que atuam & soas que atuam com RSU \\
com RSU & (D) Existência de políticas públi- \\
& cas, porém com baixo envolvi- \\
& mento das pessoas que atuam \\
& com RSU \\
& (F) Existência de políticas públicas \\
& com alto envolvimento das pes- \\
& soas que atuam com RSU
\end{tabular}

(MD) Muito desfavorável; (D) Desfavorável; (F) Favorável

Tabela 5 - Indicadores de sustentabilidade para a gestão de RSU em São Carlos na dimensão política/institucional

\begin{tabular}{c}
\hline Indicadores Tendência à sustentabilidade* \\
\hline Dimensão política/institucional
\end{tabular}

(8) Grau de estruturação da gestão de RSU na administração

(9) Grau de capacitação dos funcionários atuantes na gestão de RSU

(10) Quantidade de ações de fiscalização relacionadas à gestão de RSU promovidas pelo poder público municipal

(11) Grau de execução do Plano Municipal de RSU vigente

12) Existência de informações sobre a gestão de RSU sistematizadas e disponibilizadas para a população pública municipal

(MD) Inexistência de setor específico para RSU na administração municipal

(D) Existência de setor específico para RSU, porém não estruturado (F) Existência de setor específico para RSU devidamente estruturado

(MD) Nenhum funcionário do setor de RSU recebeu capacitação específica

(D) Apenas parte dos funcionários do setor de RSU recebeu capacitação específica

(F) Todos os funcionários do setor de RSU receberam capacitação específica

(MD) Inexistência de ações de fiscalização

(D) Existência das ações de fiscalização, porém em quantidade insuficiente

(F) Existência das ações de fiscalização em quantidade suficiente

(MD) Inexistência de Plano Municipal para RSU

(D) Existência de Plano Municipal

para RSU, porém poucas metas foram atingidas

(F) Existência de Plano Municipal para RSU com muitas metas atingidas

(MD) As informações sobre a gestão de RSU não são sistematizadas

(D) As informações sobre a gestão de RSU são sistematizadas, porém não estão acessíveis à população

(F) As informações sobre a gestão

de RSU são sistematizadas e

divulgadas de forma pró-ativa para a população

(MD) Muito desfavorável; (D) Desfavorável; (F) Favoráve resguardam-se as possibilidades de práticas ambientalmente mais adequadas de gerenciamento (da coleta à disposição final), nas quais os RSU não sejam simplesmente aterrados.

Para isso, é preciso que toda a população possa usufruir destes serviços. Portanto, a tendência mais favorável à sustentabilidade expressa a disponibilização plena dos serviços públicos de RSU; na contramão desse raciocínio, tem-se uma avaliação muito desfavorável quando ocorre baixa disponibilização. Esta em níveis intermediários ou parciais caracteriza a condição desfavorável à sustentabilidade.

A exemplo do indicador (3) descrito na dimensão ambiental, o indicador (6) também não atende a um problema priorizado pelos gestores. Entretanto, dada a relevância do tema, julgou-se pertinente sua incorporação ao conjunto final.

O indicador (7) atende ao problema da insuficiência de políticas públicas específicas para catadores de resíduos recicláveis que podem atuar num sistema formal ou informal. De acordo com Grimberg (2007), um sistema de recuperação de resíduos recicláveis que pretenda avançar na direção da sustentabilidade socioambiental pressupõe a combinação de pelo menos dois fatores: a responsabilidade dos geradores pela produção de seus resíduos e a integração dos catadores de forma autogestionária. Para isso, é importante que o Estado, no papel das prefeituras, assuma a coordenação desse processo para que o interesse público, no sentido amplo do termo, seja garantido.

Logo, considerando o papel do Estado na temática em questão, a condição mais favorável à sustentabilidade é obtida quando existem políticas públicas com alto envolvimento das pessoas que atuam com RSU; a sua inexistência impõe a condição mais desfavorável. Se existem as políticas, porém com baixo envolvimento, mantém-se a condição desfavorável à sustentabilidade. A lógica do balizamento quantitativo dos termos 'alto' e 'baixo' também pode ser adotada para a avaliação deste indicador, a critério dos usuários.

A dimensão política/institucional compreende cinco dos 15 indicadores propostos para a gestão de RSU em São Carlos, apresentados na Tabela 5. Apenas o indicador (12) foi transportado do modelo de Milanez; os demais foram adaptados a partir da literatura.

Nesta dimensão, foi unânime a opinião dos gestores quanto à priorização do item 9.a. (Tabela 1), referente à falta de organograma e de plano de carreira para o setor de RSU, como um dos principais problemas da gestão municipal. Tal fato pode comprometer profundamente a qualidade da política e da gestão de resíduos, uma vez que a instabilidade dos postos de trabalho, produzida pela intensa quantidade e rotatividade de cargos comissionados, gera graves descontinuidades de ações

Grimberg (2005) bem lembra que a gestão de RSU é atribuição de governo. O autor alerta ainda que, em tempos de valorização da "coisa pública", com participação da sociedade e compartilhamento de responsabilidades, é preciso ter cuidado para não transferir responsabilidades do Executivo para a sociedade. Obviamente, a política pública carece de participação social no que se refere à garantia 
de espaços e mecanismos institucionais para que a sociedade faça parte do processo de afirmação do interesse público comum; porém, não se deve confundir participação social com substituição do papel do Estado.

Por este motivo, é parte das funções do Poder Público trabalhar na estruturação dos setores para RSU na administração municipal. Adotando-se parâmetros qualitativos de avaliação da tendência à sustentabilidade, tem-se a condição favorável à prefeitura de investir num setor específico para RSU devidamente estruturado. A inexistência desse setor indica a tendência mais desfavorável, enquanto a existência de setor específico, porém sem a devida estruturação, aponta tendência desfavorável.

O conteúdo do indicador (9) foi inspirado no modelo de Vieira (2006), notadamente no indicador que se refere à qualificação do quadro municipal. Neste sistema, o seu cálculo se dá através do número de funcionários municipais lotados na área de limpeza urbana e atividades relacionadas a resíduos sólidos em geral que receberam algum tipo de capacitação em RSU.

Grimberg (2007) atenta que, para transformar a realidade da gestão de RSU é necessária vontade política por parte dos prefeitos, além da capacitação dos gestores municipais. Como consequência, temse uma avaliação bastante negativa em termos de sustentabilidade, a inexistência de capacitação específica dos funcionários públicos lotados nos setores relacionados a RSU. Em contrapartida, a condição favorável à sustentabilidade seria aquela em que todos os funcionários do setor de RSU estivessem bem preparados tecnicamente. Quando apenas parte do quadro de funcionários recebe algum tipo de capacitação, a tendência é considerada desfavorável à sustentabilidade.

De acordo com Fiori et al (2008), o tema da gestão ambiental urbana tem sido tratado com maior destaque no Brasil desde os anos 1990. Entretanto, ainda prevalecem grandes dificuldades, como a carência na aplicação dos instrumentos de gestão, acentuada pelo forte ritmo de urbanização e pela fragilidade nas práticas de fiscalização ambiental.

Esta última constatação também foi identificada e pontuada pelos gestores de São Carlos, o que levou à proposição do indicador (10), que mede a quantidade de ações de fiscalização relacionadas à gestão de RSU promovidas pelo Poder Público municipal. A inexistência de tais ações gera a condição mais desfavorável à sustentabilidade, ao passo que a sua existência em número suficiente indica tendências favoráveis. Se as ações existem, mas são insuficientes, a tendência é tida como desfavorável. Da mesma forma, os usuários do sistema de indicadores podem fazer o trabalho prévio de definir parâmetros quantitativos para melhor balizar o que vem a ser números suficientes ou insuficientes das ações de fiscalização no âmbito da gestão local de RSU.

Enquanto as políticas mundiais de gestão dos RSU aderem cada vez mais à noção de sustentabilidade, na prática, restam dúvidas se ela tem sido alcançada (DESMOND, 2006). A ideia de gestão sustentável de resíduos tem diferentes significados de acordo com os interesses dos grupos envolvidos, ora socioambientais, ora econômicos ou políticos.

Interesses à parte, uma gestão eficiente de RSU conta necessariamente com a implementação de programas e planos específicos para as atividades que desenvolve. É desejável, por exemplo, que um plano municipal para RSU estabeleça metas claras e factíveis, definindo-se também os meios e os prazos para a sua plena execução. Entretanto, é bastante comum a existência de contradições e divergências entre o que foi proposto no plano e o que de fato se realiza no dia-a-dia das gestões. Este é o tema do indicador (11).

Uma das formas de avaliar a tendência à sustentabilidade no âmbito das políticas, programas e planos para RSU é medir o alcance das metas. Quando muitas metas são atingidas, significa que a política caminha a favor da sustentabilidade; tende ao caminho oposto, ou seja, atinge poucas metas. A inexistência de um plano, por sua vez, caracteriza a tendência mais desfavorável à sustentabilidade.

Embora não tenha sido um problema priorizado pelos gestores, mas entendendo que a participação efetiva da sociedade na gestão dos RSU só é possível através da difusão de informações (MILANEZ; TEIXEIRA, 2003), a tempo resgatou-se o indicador proposto por Milanez para essa temática. Quando essas informações não são sequer sistematizadas, o indicador apresenta tendência muito desfavorável à sustentabilidade. Caso haja sistematização das informações, mas não acessibilidade à população, tem-se a condição desfavorável. A tendência favorável à sustentabilidade só é obtida quando as informações sobre a gestão de RSU são sistematizadas e divulgadas de forma pró-ativa para a população.

$\mathrm{Na}$ presente proposta, a dimensão cultural é composta por três indicadores (Tabela 6) que se referem a temas não abordados pelo conjunto de indicadores de Milanez. Derivaram, portanto, dos problemas identificados pelos gestores municipais.

Tabela 6 - Indicadores de sustentabilidade para a gestão de RSU em São Carlos na dimensão cultural

\begin{tabular}{ll}
\hline \multicolumn{1}{c}{ Indicadores } & \multicolumn{1}{c}{ Tendência à sustentabilidade* } \\
\hline \multicolumn{1}{c}{ Dimensão cultural } \\
(13) Variação da geração per & (MD) Taxa de variação $>1$ \\
& (D) Taxa de variação $=1$ \\
& (F) Taxa de variação $<1$ \\
(14) Efetividade de programas & (MD) Inexistência de programas \\
educativos continuados voltados & educativos \\
para boas práticas da gestão de & (D) Existência de programas edu- \\
RSU & cativos continuados, porém com \\
& baixo envolvimento da população \\
& (F) Existência de programas \\
& educativos continuados com alto \\
& envolvimento da população \\
& (MD) Ausência de divulgação de \\
(15) Efetividade de atividades de & boas práticas de gestão dos RSU \\
multiplicação de boas práticas em & ou inexistência das mesmas \\
relação aos RSU & (D) Divulgação pouco efetiva de \\
& boas práticas de gestão dos RSU \\
& (F) Divulgação efetiva de boas \\
& práticas de gestão dos RSU, inclu- \\
& sive com replicação das mesmas
\end{tabular}

(MD) Muito desfavorável; (D) Desfavorável; (F) Favorável 
A problemática da geração crescente de resíduos tem visitado a agenda ambiental de grande parte dos países e nações, permanecendo como pauta constante dos mais importantes eventos internacionais relacionados ao meio ambiente. Resultantes de sociedades caracterizadas pelo consumo predatório dos recursos naturais, os impactos gerados por essa "política do descarte" não podem mais ser ignorados.

Feldmann (2003) pondera que o problema não é o consumo em si, mas os seus padrões e efeitos no que se refere à conciliação de suas pressões sobre o meio ambiente e o atendimento às necessidades básicas da humanidade. O autor defende ainda que, para tanto, é necessário desenvolver melhor compreensão do papel do consumo na vida cotidiana das pessoas.

De um lado, o consumo abre enormes oportunidades para o atendimento de necessidades individuais de alimentação, habitação, saneamento, instrução, energia, enfim, de bem-estar material, objetivando que as pessoas possam gozar de dignidade, autoestima, respeito e outros valores fundamentais. Por outro lado, um dos grandes problemas é o fato de o consumo mundial ter se desenvolvido num ritmo e perfil de desigualdade tão grande que há necessidade emergencial de uma total mudança nos padrões de comportamento da sociedade. Afora a desigualdade, há um componente cultural extremamente complexo que se manifesta na "universalização" de estilos de vida, caracterizada pela fixação de certos padrões sociais e aspirações de consumo, no mínimo, insustentáveis (FELDMANN, 2003).

Dentro deste cenário de alinhamento às premissas preconizadas pela sustentabilidade, um bom sistema municipal de indicadores para RSU deve medir, de alguma forma, a quantidade de resíduos gerados pela sua população. O indicador escolhido para o contexto de São Carlos foi a variação da geração per capita de RSU, aferida pela razão entre a quantidade per capita em peso dos RSU gerados no ano da aplicação do indicador e a quantidade per capita de RSU gerados no ano anterior. Considera-se que os valores assim relativizados possam expressar uma medida melhor do que os valores absolutos da geração municipal de RSU, facilitando a compreensão do indicador.

Taxas de variação maiores que 1 refletem a situação mais desfavorável à sustentabilidade: significa dizer que a geração de resíduos por habitante aumentou no curto intervalo de um ano. Todavia, esse assunto merece uma análise mais profunda. É possível estabelecer, por exemplo, uma relação íntima entre o aumento da geração de resíduos e períodos de crescimento econômico, principalmente nos países periféricos e em desenvolvimento. Em momentos como estes, seria imprescindível a atuação do Poder Público no sentido de intensificar os investimentos nas políticas de minimização de resíduos, na tentativa de mitigar tais impactos.

Grimberg (2007) discute que, na linha da promoção de uma sociedade "mais sustentável", o Poder Público pode dispor, por um lado, de instrumentos e mecanismos político-econômicos que obriguem a mudança nos padrões de produção, como o lançamento de produtos efetivamente duráveis. Por outro lado, reivindica-se o estabelecimento de normas para a redução do consumo e depleção dos recursos naturais e para que os produtos pós-consumo sejam passíveis de aproveitamento integral.

Defende-se, ainda, a não produção de novos materiais e produtos que exijam novas tecnologias de fabricação e de reciclagem, com exceção da produção daqueles que possam substituir os existentes e que causem menor impacto ambiental, tanto no processo produtivo quanto na sua reciclagem. Para se aproximar do patamar da sustentabilidade, é preciso responsabilizar toda a cadeia produtiva; ao mesmo tempo, é preciso ainda fortalecer a sociedade para que ela exerça o controle desse processo (GRIMBERG, 2007).

Nesse sentido, um dos grandes desafios para as prefeituras municipais, enquanto responsáveis pela destinação dos RSU, é mudar o atual modelo de gestão de resíduos, o que significa parar de simplesmente enterrá-los e investir maciçamente num sistema público que viabilize as chamadas "boas práticas", como a coleta seletiva, a triagem e o reaproveitamento dos recicláveis, preferencialmente com inclusão social (GRIMBERG, 2007). Segundo a autora, espelhar-se em experiências exitosas constitui uma das mais importantes estratégias políticas.

Uma alternativa interessante à disposição das prefeituras é investir em programas educativos continuados voltados para estas boas práticas da gestão de RSU. Esta temática, identificada como uma das prioridades pelos gestores de São Carlos, é o objeto do indicador (14). A inexistência de programas educativos com este enfoque caracteriza a tendência mais desfavorável à sustentabilidade; a existência dos programas, porém com baixo envolvimento da população, determina a condição desfavorável. Quando os programas existirem e contarem com alta participação da sociedade, haverá a situação a favor da sustentabilidade.

O indicador (15) pode ser interpretado como uma complementação do anterior, na medida em que avalia as atividades de multiplicação das boas práticas da gestão de RSU. Uma característica particular deste indicador, portanto, é o seu caráter "solidário". Para que ele expresse a tendência favorável à sustentabilidade, é preciso haver divulgação efetiva do que se consideram boas práticas de gestão dos RSU e a sua replicação. Equivale dizer que não basta a simples existência destas práticas; importa que elas sejam reproduzidas em alguma escala, ou no próprio município ou nos municípios vizinhos.

Tanto a ausência de divulgação quanto a inexistência de boas experiências de gestão dos RSU caracterizam a tendência muito desfavorável à sustentabilidade. Se apenas a divulgação for pouco efetiva, então o indicador é avaliado desfavoravelmente.

Inevitavelmente, como discutem Fiori et al (2008), a escolha dos indicadores faz parte de um processo interativo, que por vezes fica restrito à disponibilidade de informações referentes ao fenômeno 
observado. Dessa maneira, é preferível trabalhar com um pequeno conjunto de indicadores baseados em fontes de dados confiáveis ao invés de um grande número de indicadores que teoricamente seriam interessantes, mas que em virtude da carência de dados tornam-se impraticáveis. Posteriormente, com avanços nos sistemas de informações, novos indicadores poderão ser acrescentados de acordo com as necessidades.

Ainda com relação à disponibilidade de informações, é preciso estabelecer as diferenças entre a ausência de dados e as dificuldades em acessá-los. Em geral, mesmo nas prefeituras menos estruturadas, os dados existem: o problema reside nos caminhos que precisam ser percorridos para obtê-los. Quanto à periodicidade de aplicação dos indicadores, sugere-se a princípio que eles sejam avaliados anualmente. Entretanto, esta frequência pode ser calibrada de acordo com o comportamento de cada indicador. Além disso, como os indicadores foram propostos a partir dos problemas identificados num determinado momento, que é resultado de conjunturas política, econômica e social específicas, é importante que eles sejam revistos periodicamente, a cada nova aplicação.

Para que essas tendências possam ser efetivamente avaliadas, antes da aplicação dos indicadores, devem-se definir os seus parâmetros quantitativos, nesta proposta expressos por X e Y, nos casos em que couberem. É altamente recomendável que estes valores sejam acordados entre os diversos segmentos sociais envolvidos direta ou indiretamente com a gestão de RSU em momentos oportunos e específicos para tal fim. Isto porque, por melhor que pareça, um indicador jamais será bom o suficiente se a comunidade não o julgar importante para a sua realidade. Por isso, é fundamental envolvê-la em seu processo de desenvolvimento.

Vieira (2006) argumenta que uma avaliação realizada com indicadores definidos em bases teóricas consistentes e na coerência dos processos, meios e fins, mais do que averiguar se os objetivos propostos foram alcançados, possibilita a verificação dos caminhos escolhidos e permite a orientação na tomada de decisões e, por consequência, a (re)orientação de políticas públicas.

Contudo, como assinalam Malheiros et al (2008), experiências de uso efetivo dos indicadores de sustentabilidade ainda são recentes, demandando, dessa forma, maior atenção não só por parte das instituições de pesquisa, mas também de organizações governamentais e não governamentais, enfim, dos diversos órgãos que atuam com política e gestão da sustentabilidade.

Investir na implantação de um sistema de indicadores locais é uma forma de munir a sociedade com um instrumento que, dentre outras características, tem um aspecto educacional nada desprezível. Muito além de um mero instrumento de gestão, os indicadores podem ser interpretados como importantes ferramentas pedagógicas, uma vez que despertam a atenção e o interesse da sociedade para os fenômenos que abordam.

\section{Conclusões}

O conjunto final aqui apresentado compreende 15 indicadores que se associam às cinco dimensões analisadas da sustentabilidade. A estratégia de proposição, fundamentada no contexto em que os indicadores serão aplicados, isto é, nos problemas identificados previamente e priorizados pelos gestores municipais envolvidos na gestão de RSU, permitiu a consideração efetiva das particularidades locais.

A sistematização dos indicadores considerando as cinco dimensões da sustentabilidade possibilitou a visualização dos seus princípios, geralmente tidos como plano de fundo. Em tempos de valorização deste conceito, ainda divergente, é fundamental que os instrumentos que se propõem a avaliar e monitorar as políticas e ações quanto à sustentabilidade deixem seus objetivos explícitos.

O conjunto proposto de indicadores é direcionado para a gestão pública de RSU no município de São Carlos, de forma que a geração e a divulgação sistemática de resultados - a partir de sua aplicação periódica - podem tornar as características desta gestão mais transparentes à sociedade em geral. A sensibilização e a participação dos diversos agentes e parceiros envolvidos com a gestão de RSU em São Carlos pode legitimar a implementação efetiva e permanente de um sistema de indicadores locais, possibilitando a criação de mecanismos de controle social e o estabelecimento de metas que apontem para uma gestão "mais sustentável" dos RSU.

Em nível global, tem-se observado o aumento na sofisticação teórica dos sistemas de indicadores, muito embora na prática a sua implementação não tenha acompanhado o mesmo ritmo: sobram barreiras para seu uso efetivo. Uma delas é a lacuna que existe entre a formulação e a apropriação desses indicadores, que deveria se dar no contexto do fenômeno medido, legitimado, ou seja, pelos agentes locais.

Nesse sentido, a adoção de um sistema de indicadores de sustentabilidade, adaptado às especificidades da gestão local de RSU, pode auxiliar os administradores municipais na definição das prioridades, direcionando os investimentos públicos, em geral insuficientes, para os aspectos mais problemáticos do setor.

A consolidação desse sistema pode melhorar também aspectos como a forma de engajamento dos agentes e a continuidade das ações após períodos de mudanças de gestão governamental. O principal diferencial resultante da adoção deste tipo de indicador, entretanto, será uma mudança na percepção geral da situação da gestão dos RSU, em que os princípios e dimensões da sustentabilidade passarão a ser considerados. 


\section{Referências}

DESMOND, M. Municipal solid waste management in Ireland: assessing for sustainability. Irish Geography, v. 39, n. 1, p. 22-33, 2006.

FELDMANN, F. Consumismo. In: TRIGUEIRO, A. (Coord.). Meio ambiente no século 21. Rio de Janeiro: Sextante, 2003. p. 143-157.

FIORI, S. et al. Indicadores urbanos: monitorando o ambiente construído. In: IV ENCONTRO NACIONAL DA ANPPAS, 4, 2008, Anais... Brasília, DF, 2008

GRIMBERG, E. Abrindo os sacos de "lixo": um novo modelo de gestão de resíduos está em curso no país. São Paulo, 2007. Disponível em: $<$ http://www.polis.org.br/artigo interno.asp?codigo $=176>$. Acesso em: 17 jul. 2009.

Governança democrática e um novo paradigma de gestão de resíduos sólidos. São Paulo, 2005. Disponível em: <http://www.polis. org.br/artigo interno.asp?codigo=24>. Acesso em: 17 jul. 2009.

INSTITUTO BRASILEIRO DE GEOGRAFIA E ESTATÍSTICA (IBGE). Indicadores de desenvolvimento sustentável: Brasil 2008. Rio de Janeiro, 2008. Disponível em: <http://www.ibge.gov.br/home/geociencias/ recursosnaturais/ids/default_2008.shtm>. Acesso em: 17 jul. 2009.

Pesquisa nacional de saneamento básico 2000. Rio de Janeiro, RJ, 2002. Disponível em: <http://www.ibge.gov.br/home/ estatistica/populacao/condicaodevida/pnsb/pnsb.pdf>. Acesso em: 17 jul. 2009.

KAYANO, J.; CALDAS, E.L. Indicadores para o diálogo. In: CACCIABAVA, S.; PAULICA, V.; SPINK, P. (Org.). Novos contornos da gestão local: conceitos em construção. Polis: Programa Gestão Pública e Cidadania. São Paulo: FGV/EAESP, 2002. p. 291-308.

MALHEIROS, T.F. et al. Agenda 21 nacional e indicadores de desenvolvimento sustentável: contexto brasileiro. Saúde e Sociedade, São Paulo, v. 17, n. 1, p. 7-20, 2008.
MILANEZ, B. Resíduos sólidos e sustentabilidade: princípios, indicadores e instrumentos de ação. 206 f. Dissertação (Mestrado em Engenharia Urbana) - Universidade Federal de São Carlos, São Carlos, 2002.

MILANEZ, B.; TEIXEIRA, B.A.N. Proposta de método de avaliação de indicadores de sustentabilidade para gestão de resíduos sólidos urbanos. In: FRANKENBERG, C.L.C. RAYA-RODRIGUEZ, M.T.; CANTELLI, M. (Coord.). Gestão ambiental urbana e industrial. Porto Alegre: EDIPUCRS, 2003. p. 272-283.

ORGANISATIONFORECONOMICCO-OPERATIONANDDEVELOPMENT (OECD). 2005 Annual report on sustainable development work in the OECD. 2006. Sustainable Development Studies. Disponível em: <http:// www.oecd.org/dataoecd/58/26/36654376.pdf>. Acesso em: 21 jul. 2009

PREFEITURA MUNICIPAL DE SÃO CARLOS. Secretaria Municipal de Desenvolvimento Sustentável, Ciência e Tecnologia. Departamento de Política Ambiental. Comunicação pessoal. 2007.

POLAZ, C.N.M.; TEIXEIRA, B.A.N. Utilização de indicadores de sustentabilidade para a gestão de Resíduos Sólidos Urbanos no município de São Carlos, SP. In: 24 CONGRESSO BRASILEIRO DE ENGENHARIA SANITÁRIA E AMBIENTAL, Anais... Belo Horizonte, MG. v. I, p. 203, 2007.

VAN BELLEN, H.M. Indicadores de sustentabilidade: uma análise comparativa. Rio de Janeiro: FGV, 2005.

VIEIRA, J.E.G. Modelo de avaliação de impactos socioambientais de programas de saneamento ambiental: avaliação da gestão integrada de resíduos sólidos urbanos. 360 f. Tese (Doutorado em Ciências Ambientais) - Universidade Federal de Goiás, Goiânia, 2006.

XARXA DE CIUTATS I POBLES CAP A LA SOSTENIBILITAT. Sistema municipal d'indicadors de sostenibilitat. Diputació de Barcelona: Winihard Gràfics, 2000 